\title{
VOLATILE COMPOUNDS FROM THE FLOWERS OF SPATHIPHYLLUM CANNAEFOLIUM
}

\author{
Judith A. Lewis, Christopher J. Moore, ${ }^{*}$ Mary T. Fletcher, ${ }^{*}$ Richard A. Drew* and William Kitching $\dagger$ \\ Chemistry Department, University of Queensland, St. Lucia, Queensland, Australia 4067; *Department of Primary Industries, \\ Brisbane Queensland, Australia
}

(Received 3 November 1987)

Key Word Index - Spathiphyllum cannaefolium; Araceae; 'fruit-fly lily'; flower volatiles; aromatic ethers; acetates; GC-MS.

\begin{abstract}
Headspace analysis and solvent extraction of the pollenbearing flower spike of Spathiphyllum cannaefolium have been conducted by GC-MS, to determine the basis of the flower spike's attractancy to certain fruit-fly species. The major components were benzyl acetate, methyleugenol, methylchavicol, $p$-methoxybenzyl acetate and fatty acids. Benzyl acetate is known to be attractive to $D$. cueurbitae, $D$. dorsalis and $C$. capitata (representing the three different 'male-lure categories') and methyleugenol (one of these male-lures) attracts $D$. cacuminatus, $D$. dorsalis and $D$. occipitalis. Thus the odoriferous flowerspike exhibits wide ranging attractancy and hence Spathiphyllum cannaefolium may have some application as a fruit-fly control measure for small orchards where 'methyleugenol-attracted' species (e.g. D. cacuminatus, D. dorsalis, D. occipitalis) are the dominant pests.
\end{abstract}

\section{INTRODUCTION}

Certain plant species have been reported to exhibit significant attractancy towards fruit-flies, and among the volatile compounds contained by the plants are, methyleugenol (1), Cue Lure (2) or closely related compounds. [(3) is Trimedlure, synthetic lure for Medfly-C. capitata (Wicdmann)].

The oriental fruit fly (Dacus dorsalis Hendel) has been reported [1] to be strongly attracted to the drying leaves and twigs of Palea anisata Mann (Rutaceae) and also to the flower of the 'golden flower' plant, Cassia fistula L. [2]. Methyleugenol (1) was identified as a significant if not dominant, volatile component in both cases. Leaves of the basil plant, Ocimum basilicum were also attractive to D. dorsalis, and the volatile compounds (1), methylchavicol (4) and 1,8-cineole (5) were identified from the leaves [3]. The Australian plant Zieria smithii is attractive to $D$. cacuminatus (but not $D$. tryoni) and the leaf-oil is rich in methyleugenol [4]. The orchid Dendrobium superbum is attractive $[5,6]$ to the male melon fiy, D. cucurbitae but no cvidence for the presence of either (1) or (2) was found [despite an odour similar to that of (2)], and the major volatile components were ethyl acetate and 2-tridecanone.

Our interest in the lily Spathiphyllum cannaefolium was aroused by a newspaper report [in the 'Cairns Sun' (North Queensland) 7 October 1984; p. 4] that up to 450 flies could be attracted in one day to one 'fruit-fly plant'. In Northern Thailand, the lily is grown extensively around orchard perimeters, and attracts fruit flies and thus reduce infestation of fruiting trees [Wilson, I., Avondale Nursery, Smithfield (Cairns), North Queensland,

\footnotetext{
+Author to whom correspondence should be addressed
}

personal communication]. The lily has a sweet heavy odour and is strongly attractive to flies, painting the flower spikes with Dipterex or other insecticide results in the killing of large numbers of flies. Drew observed [Drew, R. L., personal communication] that the predominant species attracted (in North Queensland) to the lily was D. musae (Tryon) (banana fly), the males of which are strngly attracted by the synthetic lure, methyleugenol [7]. The origin of the plant is unclear, but it probably was a native of South China, and is found from South-East Asia to Central and South America [Wilson, I., personal communication].

\section{RESULTS AND DISCUSSION}

The young lily flower has little odour, but after the formation of pollen in the white flower spike, the characteristic 'sweetish' odour is easily detectable, especially in the early morning. As the flower ages, pollen is lost along with the odour, and the colour changes from white to green. The volatiles of the lily were studied by headspace analysis (with air-flow and 'passive' conditions) and by solvent extraction, the details of which are in the Experimental. Headspace analysis was performed (Table 1) on both the mature flower and on one which no longer provided any obvious odour.

Passive sampling of the mature flower established the presence of five major components - benzyl acetate (6) $(59 \%)$; methyleugenol (1) $(20 \%)$ methylchavicol (4); propyl/isopropyl tetradecanoate $(6 \%)$ and $p$-methoxybenzyl acetate $(7)(\sim 3 \%)$. The structural similarity between the four aromatic compounds is clear, and their identities were confirmed by comparison of retention times and mass spectra with those of authentic samples. Methyleugenol was detected by all sampling methods which is consistent with the observation of Drew that $D$. musae 
Table 1. Compounds identified in Spathiphyllum cannaefolium by various samplings

\begin{tabular}{|c|c|c|c|c|c|c|}
\hline & \multicolumn{3}{|c|}{ Solvent extraction } & \multicolumn{2}{|c|}{ Headspace analysis } & \multirow[b]{2}{*}{$\begin{array}{l}\text { Mature flower } \\
\text { (GC insert) }\end{array}$} \\
\hline & Ether & Acetone & $\begin{array}{l}\text { Mature flower } \\
\text { (air flow) }\end{array}$ & $\begin{array}{l}\text { Aged flower } \\
\text { (air flow) }\end{array}$ & $\begin{array}{l}\text { Mature flower } \\
\text { (passive) }\end{array}$ & \\
\hline Cyclohexanone & - & $\ldots$ & - & $\ldots$ & * & -- \\
\hline Terpenes & -- & ..... & -- & -. & $* *$ & --- \\
\hline 1-H-Imidazole & $\ldots$ & $-\cdots$ & - & $* *$ & $\ldots$ & - \\
\hline Phenol & $\ldots$ & - & - & — & * & - \\
\hline Benzyl alcohol & $* *$ & $* *$ & - & -- & $-\ldots$ & \\
\hline 1,8-Cineole & $-\ldots$ & - & $* *$ & 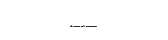 & $*$ & -- \\
\hline Benzyl acetate & - & $*$ & $* * *$ & $-\cdots$ & $* * *$ & $* * *$ \\
\hline 4-Methoxybenzyl alcohol & $* *$ & $* *$ & -- & $\ldots$ & --- & \\
\hline 1-Allyl-4-methoxybenzene & $\ldots$ & -- & $* *$ & - & ** & $* *$ \\
\hline 1-Vinyl-4-methoxybenzene & - & - & * & - & $-\ldots$ & \\
\hline Methyleugenol & $* *$ & $* *$ & $* *$ & $* *$ & $* *$ & $* * *$ \\
\hline 4-Methoxybenzyl acetate & $* *$ & $* *$ & $* *$ & $\ldots .$. & $* *$ & $* *$ \\
\hline Dodecanoic acid & $*$ & - & * & $*$ & $\ldots$ & \\
\hline Unknown $(\mathrm{BP}=43)^{+}$ & $* *$ & $* *$ & $\ldots$ &.- & $\ldots$ & \\
\hline Tetradecanoic acid & $*$ & $\ldots$ & $*$ & $* *$ & - & $\ldots$ \\
\hline Pentadecanoic acid & * & - & $*$ & $* *$ & $\ldots . .$. & $\ldots$ \\
\hline Hexadecenoic acid & * & ...-- & - & $\ldots \ldots$ & $\ldots-$ & $\ldots \ldots$ \\
\hline Hexadecanoic acid & $* * *$ & $* * *$ & $* *$ & $* * *$ &.-- & $\ldots . .$. \\
\hline Heptadecanoic acid & * & $-\ldots$ & -- & $*$ & $\ldots$ & $\ldots \ldots$ \\
\hline $\begin{array}{l}\text { Propyl/isopropyl } \\
\text { tetradecanoate }\end{array}$ & $\cdots$ & -- & -- & -- & $* *$ & $* *$ \\
\hline Octadecadienoic acid & $* * *$ & $* * *$ & - & - & $\ldots \ldots$ & $\ldots$ \\
\hline Octadecenoic acid & $-\ldots$ & - & $* *$ & $* *$ & $\ldots$ & $\ldots$ \\
\hline Octadecanoic acid & $* *$ & - & $* *$ & ** & $\ldots . .$. & $\ldots$ \\
\hline Others & $* *$ & $* *$ & $* *$ & $* * *$ & $* *$ & $* *$ \\
\hline
\end{tabular}

${ }^{*},<1 \%$ of total amount of volatile compounds as determined by GC/MS; ${ }^{* *}, 1-20 \% ;{ }^{* *},>20 \% .{ }^{+} \mathrm{BP}=$ base peak in MS.

(banana fly) was attracted strongly to this flower. Headspace analysis of the mature flower showed benzyl acetate (6) to be the major component, whereas it was essentially absent when the 'old' flower spike was examined. Benzyl acetate is one of the few compounds that is known to be attractive to D. cucurhitae, D. dorsalis and C. capitata [7] and thus the co-occurrence with methyleugenol (one of the three commercially employed male lures) accounts for the broad range attractancy of Spathiphyllum cannaefolium.

The only aromatic compound present in the headspace after the lily had lost its characteristic odour was methyleugenol. Saturated and unsaturated fatty acids dominated the chromatogram of the old flower. The major acids were hexadecanoic and octadecanoic acids, but for mature flowers, the range of fatty acids varied greatly with the sampling method. It is possible that the fatty acids, while not alone responsible for the attraction of the flies, may have enhanced the effect of other components. There is evidence, however, that the fatty acids in linseed oil exhibited significant attractancy, particularly to the melon fly (D. cucurbitae) [6]. Cineole (5), while consistently present, is found in many plants not attractive to fruit flies, and is regarded as unimportant in this respect. Methylchavicol (4) was a major constituent of the headspacc, and Chen [3] observed this compound in the basil plant (the leaf volatiles of which are attractive to $D$. dorsalis), but (4) was by itself, not attractive. One component, representing $\mathrm{ca} 10 \%$ of the components in solvent extraction, was not identified. This appeared to be aromatic and isomeric with Cue-Lure (2) with $[\mathrm{M}]^{+}=206$.

The non-availability of live flies prevented extensive testing, but both male and female $D$. tryoni exhibited some attraction toward the aromatic compounds $1,4,6$ and 7 , when open vials containing the test compounds were placed near the cage. $\beta$-Methoxybenzyl alcohol (precursor of (7)) also exhibited some attractancy under these conditions.

\section{EXPERIMENTAL.}

Headspace analysis. This procedure involved adsorptive trapping of the volatiles onto a porous polymer followed by thermal desorption into a combined GC-MS system. Thermal desorption is preferable to solvent extraction, as no work-up is required and 'solvent masking' of very volatile components in the gas chromatograph is not a problem. Tenax GC and TA [8] were the chosen adsorbents because of their thermal stability $(350-400 \%$, and the very low polarity of these polymers (based on 2,6-diphenylene oxide) renders water retention unimportant. The polymer has a high affinity for organic compounds [9], but no attempt was made to calibrate the efficiency of adsorption for different functionalities, since only a qualitative profile could be obtained. After conditioning the Tenax $3 \mathrm{hr}$ at 270 ; He flow $(20-40 \mathrm{ml} / \mathrm{min})$ some artifacts remain and a list of thesc (which include undecane, toluene, xylenes etc) is available [8].

The volatiles were collected on Tenax GC or TA (ca $200 \mathrm{mg}$ ) held in glass tubes $(150 \mathrm{~mm} ; 6 \mathrm{~mm}$ diameter $)$ by silanized glass 
<smiles>C=CCc1ccc(OC)c(OC)c1</smiles>

1<smiles>CC(=O)Oc1ccc(CC(C)(C)C)cc1</smiles><smiles>CC(=O)OC1CCCCC1C</smiles><smiles>C=CCc1ccc(OC)cc1</smiles>

4<smiles>CC1(C)OC2CCC1CC2</smiles>

5<smiles>CC(=O)OCc1ccccc1</smiles>

6<smiles>COc1ccc(CC(C)=O)cc1</smiles>

7 wool plugs, all connections were by silastic tubing, and thus occasionally some silicon-containing compounds were detected. The volatiles of the strong smelling spike were collected by removing the spike and placing it in an all glass chamber which was sealed with a flangc joint. Purificd air was strcamed through a Tenax-filled pre-tube (to filter any organic material) into the chamber $(50-100 \mathrm{ml} / \mathrm{min})$ and two outlets permitted duplicate sampling simultaneously. At each outlet, two tubes were connected in series, the first to collect the volatiles and the second to prevent atmospheric contamination. The volatiles were sampled for one hour and then the tubes were sealed with Teflon caps and stored.

Reproducible results were obtained with this system. However two problems were associated with it--the very volatile components may not have been efficiently trapped with the air flow, and 'cutting off' the flower spike was a destructive sampling technique, as flower production was somewhat irregular. A 'passive' sampling method was employed which involved mounting the Tenax-filled tube (by copper wire suspension) beside the flower and the two were covered by a cylinder $(\sim 100 \mathrm{ml})$ which served to concentrate the volatiles. This was set up at night, and the tube removed and sealed the next morning. The 'passive' method was used routinely, although the results matched those under conditions of air-flow.

The tubes were then transferred to the GC-MS for thermal desorption, utilizing a unit consisting of two metal blocks containing cartridge heaters which were pre-heated to $200^{\circ}$. The adsorption tube was connected to the helium flow at one end, and a specially adapted needle at the other. After c $33 \mathrm{~min}$, the tube was placed between the hinged heating blocks which were clamped, and the needle inserted into the injector port. The plant volatiles were desorbed (for $3 \mathrm{~min}$ ) from the Tenax and carried by the He flow onto the GC-column at $0^{\circ}$. The ncedle was removed from the injector port, the heating block unclamped and the GC oven temperature ramped. Reproducible results were achieved with this system, on a Finnigan Mat Automated GC/MS [10].

Solvent extraction. The strongly smelling flower spikes were cut into small pieces and extracted for $c a 24 \mathrm{hr}$ with either $\mathrm{Me}_{2} \mathrm{CO}$ or $\mathrm{Et}_{2} \mathrm{O}$. The extracts were examined directly by GC-MS.

Spathiphyllum cannaefolium were purchased from the Avondale Nursery (Mr I. Wilson), Smithfield 4871 (via Cairns), Queensland, and air-freighted to Brisbane. These plants were extremely hardy and thrived in a sunny room (tenth floor) on the northern side of the Chemistry Building, with a minimum of attention.

Acknowledgements - We are grateful to Mr Ian Wilson (Avondale Nursery) for information on Spathiphyllum cannaefolium and to Miss Lily Murphy for observant fieldwork.

\section{REFERENCES}

1. Tuthill, L. D. (1953) Proc. Hawaiian Entomol. Soc. 15, 265.

2. Kawano, Y., Mitchell, W. C. and Matsumato, H. (1968) J. Econ. Entomol. 61, 986.

3. Chen, Y. L., Yee, J. Y. and Lee, S. L. (1970) Chem. Abs. 724433q.

4. Fletcher, B. S., Bateman, M. A., Hart, N. K. and Lamberton, J. A. (1975) J. Econ. Entomol. 68, 815.

5. Flath, R. A. and Ohinata. K. (1982) J. Agric. Food Chem. 30 , 841.

6. McPhail, M. (1943) J. Econ. Entomol. 36, 426.

7. Metcalf, R. L., Mitchell, W. C. and Metcalf, E. R. (1983) Proc. Natl Acad. Sci. U.S.A. 80, 3143.

8. Macleod, G. and Ames, J. M. (1986) J. Chromatogr. 355, 393.

9. Novotny, M. L. and Bartle, K. D. (1974) Chromatographia 7, 333.

10. Lewis, J. A. (1987) Ph.D. Thesis, University of Queensland. 